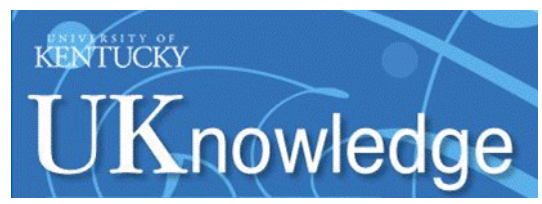

University of Kentucky

UKnowledge

CRVAW Faculty Journal Articles

Center for Research on Violence Against

Women

2000

\title{
Intimate Partner Violence and Cervical Neoplasia
}

Ann L. Coker

University of South Carolina - Columbia, ann.coker@uky.edu

Maureen Sanderson

University of South Carolina - Columbia, msanderson@mmc.edu

Mary Kay Fadden

University of South Carolina - Columbia, mary.k.fadden@utb.edu

Lucia Pirisi

University of South Carolina - Columbia, pirisi@uscmed.sc.edu

Follow this and additional works at: https://uknowledge.uky.edu/crvaw_facpub

Part of the Female Urogenital Diseases and Pregnancy Complications Commons, Obstetrics and Gynecology Commons, Oncology Commons, and the Public Health Commons

Right click to open a feedback form in a new tab to let us know how this document benefits you.

\section{Repository Citation}

Coker, Ann L.; Sanderson, Maureen; Fadden, Mary Kay; and Pirisi, Lucia, "Intimate Partner Violence and Cervical Neoplasia" (2000). CRVAW Faculty Journal Articles. 115.

https://uknowledge.uky.edu/crvaw_facpub/115

This Article is brought to you for free and open access by the Center for Research on Violence Against Women at UKnowledge. It has been accepted for inclusion in CRVAW Faculty Journal Articles by an authorized administrator of UKnowledge. For more information, please contact UKnowledge@lsv.uky.edu. 


\section{Intimate Partner Violence and Cervical Neoplasia}

\section{Digital Object Identifier (DOI)}

http://dx.doi.org/10.1089/15246090050200051

\section{Notes/Citation Information}

Published in Journal of Women's Health \& Gender-Based Medicine, v. 9, no. 9, p. 1015-1023.

This is a copy of an article published in the Journal of Women's Health \& Gender-Based Medicine @ 2000 Mary Ann Liebert, Inc.; Journal of Women's Health \& Gender-Based Medicine is available online at: http://online.liebertpub.com/loi/jwh.1

Dr. Ann Coker had not been a faculty member of the University of Kentucky at the time of publication. 


\title{
Intimate Partner Violence and Cervical Neoplasia
}

\author{
ANN L. COKER, Ph.D., ${ }^{1}$ MAUREEN SANDERSON, Ph.D., ${ }^{1}$ MARY KAY FADDEN, M.P.H., ${ }^{1}$ \\ and LUCIA PIRISI, M.D. ${ }^{2}$
}

\begin{abstract}
Intimate partner violence (IPV) is associated with a range of adverse physical health outcomes, including chronic and infectious diseases. An emerging literature suggests that partner violence and specifically sexual violence may be associated with an increased risk of cervical neoplasia. To assess the risk of preinvasive and invasive cervical cancer in a cross-sectional study of women screened for IPV by type, frequency and duration, 1152 women ages 18-65 were recruited from family practice clinics in 1997-1998. They were screened for IPV during a brief in-clinic interview, and health history and current status were assessed in a follow-up interview. Of 1152 women surveyed, $14(1.2 \%)$ reported cervical cancer, and 20.3\% $(n=234)$ reported treatment for cervical neoplasia. Ever experiencing IPV was associated with an increased risk of invasive cervical cancer (adjusted relative risk $[a R R]=4.28 ; 95 \%$ CI 1.94, 18.39) and with preinvasive cervical neoplasia $(a R R=1.47 ; 95 \%$ CI 1.16, 1.82). This association was stronger for women experiencing physical or sexual IPV than for women experiencing psychological IPV. Women with cervical cancer reported being in violent relationships longer and experiencing more frequent physical and sexual assaults and more IPV-associated injuries than did controls. This exploratory study suggests that IPV may increase a woman's risk of cervical neoplasia. The mechanism by which IPV effects cervical neoplasia may be indirect through psychosocial stress or negative coping behaviors or direct through sexual assaults and transmission of human papillomavirus (HPV).
\end{abstract}

\section{INTRODUCTION}

$\mathbf{I}_{\mathrm{P}}$ NTIMATE PARTNER VIOLENCE (IPV) is a significant public health problem that has both short-term and long-term physical and mental health consequences for women and their families. ${ }^{1,2}$ Prevalence estimates for current IPV among women receiving care in primary healthcare settings range between $7 \%$ and $29 \% .^{3-6}$ Women experiencing
IPV use a disproportionate share of healthcare services, making more visits to emergency departments, primary care facilities, and mental health agencies than nonabused women. ${ }^{7-12}$ Physical partner violence has mental and physical health consequences ranging from depression, anxiety, and posttraumatic stress disorder to irritable bowel syndrome, migraine headaches, angina, sexually transmitted infections (STI),

\footnotetext{
${ }^{1}$ Department of Epidemiology and Biostatistics, University of South Carolina, School of Public Health, Columbia, South Carolina.

${ }^{2}$ Department of Pathology, University of South Carolina, School of Medicine, Columbia, South Carolina.

Funded by R49 CCR412752 of the CDC National Center for Injury Prevention and Control and the Disabilities Prevention Program of the National Center for Environmental Health and by R29-CA-57466 from the National Institutes of Health.
} 
pelvic inflammatory disease, chronic pelvic pain, and bladder, kidney, or other urinary tract infections. ${ }^{1,2,13-22}$

The mechanism by which sexual IPV affects cervical neoplasia risk may be direct, through repeated sexual assaults that cause cervical trauma, which in combination with introduction of human papillomavirus (HPV) might begin the cervical carcinogenic process. ${ }^{24}$ Alternatively, physical or sexual IPV may affect cervical cancer risk indirectly through increasing chronic stress, which may suppress immune function ${ }^{25-28}$ and thereby reduce the body's ability to mount an effective immune response to HPV infection ${ }^{29,30}$ or to appropriately detect and eliminate cervical tumor cells. ${ }^{31,32}$

The purpose of this exploratory study was twofold. First, we evaluated the association between IPV (by type of violence, duration, and frequency of violence) and cervical neoplasia (by cervical cancer or treatment for cervical lesions). Second, we explored the potential mechanism by which IPV might affect cervical neoplasia risk. To our knowledge, this is the first study to address IPV and cervical neoplasia, including cancer.

\section{MATERIALS AND METHODS}

\section{Data collection}

In this cross-sectional study, trained recruiters approached and interviewed 1152 women seeking medical care in two university-associated family practice clinics from February 1997 through January 1999. Eligible subjects were women ages 18-65 who were insured by either Medicaid or a managed care provider. Because we wanted to focus on partner violence, including sexual violence, in intimate relationships, we included only women who had ever been in an intimate (meaning sexual) relationship with a man for at least 3 months. Study participation included a 5-10-minute in-clinic interview to screen for partner violence and a 30-45-minute telephone interview to assess the woman's medical history and current health status. We used computer-assisted interviewing for both in-clinic and telephone interviews to reduce errors and rapidly provide scale scores for IPV measures. In-clinic interviewers were women graduate students who received extensive training in asking these sensitive questions, in active listening, and in provid- ing women with community resources. Women were reimbursed for their time in completing these interviews. Women currently in abusive relationships were counseled by recruiters and referred to local services for victims. For safety reasons, women currently in violent relationships were given the option to complete this longer interview in the clinic. All women signed consent forms. The University of South Carolina Institutional Review Board approved the project.

\section{Measures of IPV}

We characterized IPV by (1) the timing of the violence (in any past or current intimate relationship), (2) the type of violence (physical, sexual, or psychological violence), and (3) frequency of the violence and injury. The instrumentation methods for the study appear elsewhere. ${ }^{13,33} \mathrm{We}$ provide a brief overview here.

We used a modified (12-item) version of the 25item Index of Spouse Abuse-Physical ${ }^{34,35}$ (ISA-P) to measure current or recent physical IPV and sexual IPV and the Women's Experience with Battering (WEB) Scale to assess battering. ${ }^{36-38} \mathrm{We}$ also assessed past physical, sexual, and psychological IPV using a modification of the widely used Abuse Assessment Screen. ${ }^{39}$ We combined past and current IPV experience to hierarchically categorize ever experiencing IPV by type: (1) physical or sexual violence or both with or without psychological IPV, (2) psychological violence, defined to include either psychological battering or emotion abuse without physical or sexual violence, and (3) never experiencing IPV as the referent group. The majority $(88 \%)$ of women who experienced physical or sexual violence also reported psychological violence.

Psychometric properties of IPV measures. The WEB Scale has good construct validity, accurately discriminates battered from nonbattered women, ${ }^{36,38}$ and shows strong internal consistency reliability (Cronbach's alpha $=0.95$ in our sample of women receiving primary care). The WEB Scale measures battering by operationalizing women's psychological vulnerability or their perceptions of susceptibility to physical and psychological danger or loss of power and control in a relationship with a male partner. ${ }^{36,37}$ The ISA$\mathrm{P}$ was designed to measure the frequency and severity of physical assaults by an intimate partner. ${ }^{34}$ As reported by Attala et al. ${ }^{35}$ in a valida- 
tion study of 135 women recruited from a battered women's shelter and 48 nonabused women, the 25-item measure is valid and reliable. The sensitivity and specificity for a cut point of $>2$ were $87.5 \%$ and $96 \%$, respectively, and the alpha coefficient was 0.97 . We assessed the reliability of the full and modified scales in this study; the Cronbach's alpha coefficients for the full 25-item scale ( $n=89$ pilot study) was 0.95 , and the coefficient for the full sample for the reduced 12-item scale changed minimally (alpha $=0.91$ ). The Abuse Assessment Screen (AAS) ${ }^{39}$ has been widely used in clinical settings to rapidly assess IPV.

Psychological IPV was assessed for the current or more recent relationship as well as in any past relationship. Women scoring as battered (WEB $\geq 20$ ) yet not scoring as physically assaulted (ISA-P $<3$ ) were defined as experiencing psychological IPV in a current or most recent relationship. Women who reported emotional abuse without physical abuse on the AAS were coded as experiencing psychological IPV in a past relationship.

Frequency and duration of IPV and injuries. We created frequency and duration scores for physical and sexual IPV. Duration was the length of time the women reported being in an intimate relationship in which there was IPV by the type of violence. Frequency of physical IPV was assessed based on the woman's report of how frequently the partner hit, slapped, kicked, or otherwise physically hurt her during the time they were together as a couple. Frequency of sexual IPV was assessed based on the woman's report of how frequently the partner forced sex on her during their relationship. We addressed a dose-response relationship between IPV and cervical neoplasia by evaluating risk associated with (1) years in a violent relationships, (2) frequency of injuries, and (3) a cumulative duration times frequency score for physical and sexual IPV. We created tertiles of frequency-duration scores based on the distribution of these scores among controls who experienced IPV. There is overlap between the two measures of sexual and physical IPV frequency and duration. Women reporting higher sexual IPV scores also report higher physical IPV scores. However, we present the two measures separately because the frequency measures are specific to the type of violence and tap different potential mechanisms.

\section{Demographics}

The following demographic characteristics were assessed during the 5-10-minute in-clinic screening interview: the woman's current marital status, age, race/ethnicity, education, usual occupation, age at first sexual intercourse, lifetime number of male sex partners, STI history, pregnancy history, and cigarette smoking history. Given the sensitive nature of the screening questions and limited interview time, we did not assess childhood physical or sexual abuse. We did ask about the father's abusive behavior toward the woman's mother. We used this as a crude indicator of possible child abuse.

\section{Cervical neoplasia}

In a subsequent 30-45-minute telephone survey conducted 1-2 weeks after the in-clinic survey, we assessed the prevalence of a range of health outcomes ${ }^{13}$ using a modified National Health Interview Survey. ${ }^{40} \mathrm{We}$ asked women if they had ever been diagnosed with a specific (listed) cancer and if they had ever been treated with "cryotherapy, laser therapy, or any other treatment for an abnormal Pap smear." We use the label "cervical dysplasia" to refer to women who were treated for an abnormal Pap smear but who did not have cervical cancer. We used age at first IPV experience as the reference date to correctly sequence cervical neoplasia as having occurred only after the first IPV experience. From these questions, we created the mutually exclusive outcome variables of interest: cervical cancer cases $(n=14)$, cervical dysplasia cases $(n=234)$, and women with no reported history of cervical neoplasia or other cancer as controls $(n=847)$. We additionally reviewed the medical records of cervical cancer patients and those with dysplasia to confirm the self-reported cervical neoplasia. We did not have access to cervical cytology or biopsy results to fully document the cervical lesions.

\section{Statistical analysis}

Unconditional polytomous multivariate logistic regression ${ }^{41}$ was used to model the association between IPV by type and cervical neoplasia, adjusting for age as a continuous variable, and cigarette smoking (pack-years). Although this is a cross-sectional study, we created time-framed exposures for smoking and partner violence, 
Table 1. Distribution of Risk Factors for Cervical Neoplasia

\begin{tabular}{|c|c|c|c|c|c|}
\hline \multirow[b]{2}{*}{ Risk factor } & \multirow{2}{*}{$\begin{array}{c}\text { Cervical } \\
\text { cancer } \\
(\mathrm{n}=14)\end{array}$} & \multirow{2}{*}{$\begin{array}{c}\text { Cervical } \\
\text { dysplasia } \\
(\mathrm{n}=234)\end{array}$} & \multirow[b]{2}{*}{$\begin{array}{l}\text { Controls } \\
(\mathrm{n}=847)\end{array}$} & \multicolumn{2}{|c|}{ Relative Risk (95\% CI) } \\
\hline & & & & $\begin{array}{l}\text { Cervical cancer } \\
\text { cases vs. controls }\end{array}$ & $\begin{array}{c}\text { Cervical dysplasia } \\
\text { vs. controls }\end{array}$ \\
\hline $\operatorname{Age}^{\mathrm{a}}$ & $38.9 \pm 8.3$ & $36.7 \pm 9.7$ & $37.9 \pm 11.6$ & $1.02(0.98,1.07)$ & $0.99(0.98,1.01)$ \\
\hline Age at first intercourse ${ }^{a}$ & $15.5 \pm 2.9$ & $17.3 \pm 2.9$ & $17.6 \pm 3.3$ & $0.85(0.75,0.97)$ & $0.98(0.93,1.02)$ \\
\hline Lifetime number of male sex partners $\mathrm{a}^{\mathrm{a}}$ & $8.1 \pm 6.4$ & $8.5 \pm 15.6$ & $7.7 \pm 17.0$ & $1.00(0.97,1.03)$ & $1.00(0.99,1.01)$ \\
\hline No. of pregnancies ${ }^{\mathrm{a}}$ & $2.4 \pm 1.1$ & $2.4 \pm 1.7$ & $2.4 \pm 2.0$ & $1.13(0.91,1.40)$ & $0.99(0.94,1.07)$ \\
\hline White race ${ }^{\mathrm{b}}$ & $35 . \overline{7} \%$ & $35 . \overline{9} \%$ & $38 . \overline{7} \%$ & $0.88(0.29,2.63)$ & $0.91(0.70,1.16)$ \\
\hline Medicaid insurance ${ }^{\mathrm{b}}$ & $14.3 \%$ & $18.0 \%$ & $22.6 \%$ & $0.57(0.13,2.56)$ & $0.75(0.56,1.07)$ \\
\hline \multicolumn{6}{|l|}{ Education ${ }^{\mathrm{b}}$} \\
\hline$<$ High school & $28.6 \%$ & $9.0 \%$ & $12.4 \%$ & $2.65(0.79,8.75)$ & $0.72(0.46,1.09)$ \\
\hline HS graduate or GED & $14.3 \%$ & $20.1 \%$ & $21.4 \%$ & $0.77(0.16,3.64)$ & $0.88(0.65,1.21)$ \\
\hline$>$ HS education & $57.1 \%$ & $70.9 \%$ & $66.2 \%$ & $1.00 \operatorname{Ref}^{\mathrm{c}}$ & 1.00 Ref \\
\hline Currently divorced or separated ${ }^{b}$ & $50.0 \%$ & $24.8 \%$ & $19.3 \%$ & $4.14(1.45,11.62)$ & $1.29(0.96,1.67)$ \\
\hline $\begin{array}{l}\text { Ever had sexually transmitted } \\
\text { infection }^{\text {b }}\end{array}$ & $35.7 \%$ & $35.7 \%$ & $17.4 \%$ & $3.54(1.22,10.09)$ & $1.89(1.51,2.33)$ \\
\hline Ever smoked cigarettes ${ }^{\mathrm{b}}$ & $78.6 \%$ & $37.6 \%$ & $35.1 \%$ & $6.64(1.87,22.51)$ & $1.11(0.83,1.39)$ \\
\hline Nonsmoker & $21.4 \%$ & $62.4 \%$ & $64.9 \%$ & $1.00 \operatorname{Ref}^{\mathrm{c}}$ & 1.00 Ref \\
\hline Current smoker ${ }^{\mathrm{b}}$ & $78.6 \%$ & $28.6 \%$ & $26.0 \%$ & $10.09(2.87,33.16)$ & $1.12(0.86,1.44)$ \\
\hline \multicolumn{6}{|l|}{ Years smoked cigarettes ${ }^{b}$} \\
\hline $20+$ & $14.3 \%$ & $0.4 \%$ & $1.2 \%$ & $32.38(5.42,126.86)$ & $0.43(0.06,2.21)$ \\
\hline $10-20$ & $28.6 \%$ & $23.1 \%$ & $19.6 \%$ & $4.36(0.98,18.60)$ & $1.18(0.88,1.55)$ \\
\hline $5-10$ & $14.3 \%$ & $8.1 \%$ & $7.8 \%$ & $5.36(0.97,29.87)$ & $1.07(0.67,1.62)$ \\
\hline \multirow{2}{*}{\multicolumn{6}{|c|}{ Packs ususally smoked }} \\
\hline & & & & & \\
\hline $2+$ & $0.0 \%$ & $1.7 \%$ & $3.2 \%$ & $\mathrm{NE}^{\mathrm{c}}$ & $0.60(0.22,1.46)$ \\
\hline $1-2$ & $35.6 \%$ & $11.5 \%$ & $10.7 \%$ & $9.75(2.36,37.04)$ & $1.10(0.74,1.57)$ \\
\hline$<1$ & $43.0 \%$ & $24.4 \%$ & $21.0 \%$ & $6.07(1.53,22.91)$ & $1.17(0.87,1.52)$ \\
\hline \multicolumn{6}{|l|}{ Pack-years smoking b } \\
\hline $10+$ & $28.6 \%$ & $12.0 \%$ & $11.5 \%$ & $7.39(1.67,30.50)$ & $1.07(0.73,1.53)$ \\
\hline $5-10$ & $14.3 \%$ & $8.1 \%$ & $9.1 \%$ & $4.70(0.79,26.21)$ & $0.94(0.60,1.44)$ \\
\hline$<5$ & $35.7 \%$ & $17.5 \%$ & $14.4 \%$ & $7.35(1.77,28.56)$ & $1.21(0.87,1.64)$ \\
\hline
\end{tabular}

${ }^{\mathrm{a}}$ Mean $\pm \mathrm{SD}$.

b\% within case group.

'Ref, referent; NE, not estimable.

which stipulated that the exposures measured had to have occurred prior to disease development (age at cancer diagnosis or cervical neoplasia treatment). We enumerated only IPV experience and smoking duration prior to these ages of diagnosis.

Because logistic regression provides odds ratios (OR) that are biased estimates of the relative risk (RR) if an outcome is not rare $(>10 \%$ ) (and cervical dysplasia was not rare), we used the method of Zhang and $\mathrm{Yu}^{42}$ to convert OR to RR.

We hypothesized that IPV might increase the risk of cervical neoplasia directly by increasing the risk of acquiring an STI, specifically HPV. To address the role of STI in the association between IPV and cervical neoplasia, we stratified by STI status to determine whether STI might help clarify the mechanism for the association. ${ }^{43}$

\section{RESULTS}

\section{Response rates}

Eleven percent of 1538 eligible women approached for participation $(n=174)$ refused. Refusers were significantly more likely to be insured by Medicaid (32\%) than were responders (25\%). We have no additional demographic data with which to characterize refusers relative to responders. Of the responders, $14.1 \%$ did not complete the health assessment interview (192 of 1364) or had missing data on several response variables (20 of 1364). Thus, 1152 women were included in these analyses (75\% response rate). Women who completed the in-clinic interview but not the health assessment interview $(n=192)$ were younger and significantly more likely to be in a 
Table 2. Risk of Cervical Neoplasia Associated with Intimate Partner Violence by Type, SeVerity, and Duration of Violence

\begin{tabular}{|c|c|c|c|c|c|}
\hline \multirow[b]{2}{*}{ Intimate partner violence (IPV) } & \multirow{2}{*}{$\begin{array}{c}\text { Cervical } \\
\text { cancer } \\
(\mathrm{n}=14)\end{array}$} & \multirow{2}{*}{$\begin{array}{c}\text { Cervical } \\
\text { dysplasia } \\
(\mathrm{n}=234)\end{array}$} & \multirow[b]{2}{*}{$\begin{array}{l}\text { Controls } \\
(\mathrm{n}=847)\end{array}$} & \multicolumn{2}{|c|}{ Adjusted $R R^{\mathrm{a}}(95 \% \mathrm{CI})$} \\
\hline & & & & $\begin{array}{l}\text { Cervical cancer } \\
\text { cases vs. controls }\end{array}$ & $\begin{array}{l}\text { Cervical dysplasia } \\
\text { vs. controls }\end{array}$ \\
\hline $\begin{array}{l}\text { Ever experienced any IPV } \\
\text { (physical, sexual, or psychological) }\end{array}$ & $85.7 \%$ & $62.4 \%$ & $50.8 \%$ & $4.47(1.07,19.07)$ & $1.60(1.18,2.15)$ \\
\hline \multicolumn{6}{|l|}{ Ever experienced IPV by type } \\
\hline No IPV & $14.3 \%$ & $37.6 \%$ & $49.2 \%$ & $1.00 \operatorname{Ref}^{\mathrm{a}}$ & 1.00 Ref \\
\hline Psychological, no physical IPV & $14.3 \%$ & $13.7 \%$ & $11.8 \%$ & $3.77(0.53,25.00)$ & $1.38(0.96,1.92)$ \\
\hline Physical, no sexual IPV & $14.3 \%$ & $25.2 \%$ & $19.5 \%$ & $1.80(0.28,12.81)$ & $1.50(1.11,1.95)$ \\
\hline Physical and sexual IPV & $57.1 \%$ & $23.5 \%$ & $19.5 \%$ & $7.18(1.51,31.54)$ & $1.44(1.07,1.90)$ \\
\hline \multicolumn{6}{|l|}{ Years in violent relationship } \\
\hline No IPV & $14.3 \%$ & $45.7 \%$ & $54.9 \%$ & 1.00 Ref & 1.00 Ref \\
\hline $1-5$ & $14.3 \%$ & $28.2 \%$ & $25.1 \%$ & $1.68(0.23,11.27)$ & $1.24(0.93,1.62)$ \\
\hline $5-10$ & $21.4 \%$ & $11.1 \%$ & $8.4 \%$ & $6.59(1.07,36.37)$ & $1.44(0.97,2.03)$ \\
\hline $10+$ & $50.0 \%$ & $15.0 \%$ & $11.6 \%$ & $13.04(2.64,53.29)$ & $1.49(1.04,2.04)$ \\
\hline Wald chi-square for trend ( $p$ value) & & & & $12.47(0.0004)$ & $6.71(0.01)$ \\
\hline \multicolumn{6}{|l|}{ IPV-associated injury score } \\
\hline No injury & $28.6 \%$ & $66.7 \%$ & $72.1 \%$ & 1.00 Ref & 1.00 Ref \\
\hline $1-2$ & $35.7 \%$ & $23.1 \%$ & $18.4 \%$ & $3.04(0.84,10.75)$ & $1.26(0.94,1.64)$ \\
\hline$>2$ & $35.7 \%$ & $10.3 \%$ & $9.4 \%$ & $4.54(1.19,16.77)$ & $1.14(0.76,1.67)$ \\
\hline Wald chi-square test for trend ( $p$ value) & & & & $5.57(0.02)$ & $1.57(0.21)$ \\
\hline \multicolumn{6}{|l|}{ Physical IPV score ${ }^{\mathrm{b}}$} \\
\hline No physical IPV & $28.6 \%$ & $58.5 \%$ & $64.7 \%$ & 1.00 Ref & 1.00 Ref \\
\hline $\mathrm{Q} 1^{\mathrm{a}}$ & $0.0 \%$ & $13.7 \%$ & $11.6 \%$ & $\mathrm{NE}^{\mathrm{a}}$ & $1.20(0.83,1.68)$ \\
\hline $\mathrm{Q} 2$ & $21.4 \%$ & $12.4 \%$ & $12.0 \%$ & $3.22(0.70,145.30)$ & $1.10(0.74,1.55)$ \\
\hline Q3 & $50.0 \%$ & $15.4 \%$ & $11.7 \%$ & $6.84(1.88,23.69)$ & $1.39(0.98,1.90)$ \\
\hline \multirow{2}{*}{\multicolumn{6}{|c|}{ Sexual IPV score ${ }^{b}$}} \\
\hline & & & & & \\
\hline No sexual IPV & $42.9 \%$ & $76.5 \%$ & $80.5 \%$ & 1.00 Ref & 1.00 Ref \\
\hline Q1 & $0 \%$ & $4.7 \%$ & $6.1 \%$ & NE & $0.83(0.45,1.42)$ \\
\hline Q2 & $7.1 \%$ & $10.7 \%$ & $6.8 \%$ & $1.40(0.16,11.79)$ & $1.49(0.98,2.05)$ \\
\hline Q3 & $50.0 \%$ & $8.1 \%$ & $6.5 \%$ & $11.15(3.58,32.70)$ & $1.31(0.83,1.95)$ \\
\hline Wald chi-square test for trend ( $p$ value) & & & & $13.89(0.0002)$ & $3.07(0.08)$ \\
\hline
\end{tabular}

${ }^{a}$ Ref, referent; $Q$, quartile; NE, not estimable; RR, relative risk.

bcore includes frequency of violence multiplied by duration in a violent relationship.

current violent relationship $(\mathrm{RR}=2.6)$ than were women who completed the health assessment.

The prevalence of partner violence was relatively high in this clinic population; $53.7 \%$ had ever experienced some type of IPV. Among those reporting IPV, 77\% experienced physical or sexual IPV, and 23\% experienced psychological violence without physical or sexual IPV.

Table 1 provides our assessment of risk factors for cervical neoplasia in this population. Cervical cancer patients had earlier ages at first intercourse and were more likely to be divorced or separated, and to smoke than other women. Those with cervical cancer or cervical dysplasia were also more likely than controls to have ever had STI.
Table 2 presents the frequency of IPV by type among women with cervical cancer, cervical dysplasia, and controls. Ever experiencing IPV was more strongly associated with cervical cancer $(\mathrm{RR}=4.47 ; 95 \% \mathrm{CI} 1.07,19.07)$ than with cervical dysplasia $(R R=1.60 ; 95 \%$ CI 1.18, 2.15). For cervical cancer cases relative to controls, the association with IPV was strongest for physical and sexual IPV (adjusted RR [aRR] = 7.18). Increasing duration in a violent relationship, increasing IPVassociated injuries, and increasing physical and sexual IPV frequency-duration scores were all associated with increasing cervical cancer risk in a dose-dependent manner. For cervical dysplasia relative to controls, physical or sexual IPV was significantly associated with increased risk, yet 
Table 3. Risk of Cervical Neoplasia Associated with Physical and Sexual IPV Score by STI History

\begin{tabular}{|c|c|c|c|c|}
\hline & \multicolumn{2}{|c|}{ Cervical cancer } & \multicolumn{2}{|c|}{ Cervical dysplasia } \\
\hline & Ever STI & Never STI & Ever STI & Never STI \\
\hline \multicolumn{5}{|l|}{ Sexual IPV score ${ }^{a}$} \\
\hline \multirow[t]{2}{*}{ Quartile 3} & $4 / 17^{\mathrm{b}}$ & $3 / 38$ & $7 / 17$ & $12 / 38$ \\
\hline & $10.4(1.8,51.5)$ & $11.2(2.5,44.9)$ & $0.8(0.3,1.7)$ & $1.3(0.7,2.1)$ \\
\hline \multirow[t]{2}{*}{ Quartiles 1-2 } & $0 / 38$ & $1 / 72$ & $20 / 38$ & $16 / 72$ \\
\hline & $\mathrm{NE}^{\mathrm{c}}$ & $2.0(0.2,17.4)$ & $1.0(0.5,1.6)$ & $1.0(0.6,1.6)$ \\
\hline \multirow[t]{2}{*}{ No sexual IPV } & $2 / 92$ & $4 / 590$ & $50 / 92$ & $129 / 590$ \\
\hline & 1.0 $\operatorname{Ref}^{\mathrm{c}}$ & 1.0 Ref & 1.0 Ref & 1.0 Ref \\
\hline \multicolumn{5}{|l|}{ Physical IPV score ${ }^{\mathrm{a}}$} \\
\hline \multirow[t]{2}{*}{ Quartile 3} & $4 / 28$ & $3 / 71$ & $10 / 28$ & $26 / 71$ \\
\hline & $4.1(0.7,21.7)$ & $10.0(1.7,51.0)$ & $0.6(0.3,1.3)$ & $1.5(1.1,2.1)$ \\
\hline \multirow[t]{2}{*}{ Quartiles 1-2 } & $0 / 62$ & $3 / 138$ & $34 / 62$ & $27 / 138$ \\
\hline & $\mathrm{NE}$ & $5.2(0.9,28.9)$ & $0.9(0.5,1.5)$ & $0.9(0.6,1.4)$ \\
\hline \multirow[t]{2}{*}{ No sexual IPV } & $2 / 65$ & $2 / 491$ & $33 / 57$ & $104 / 491$ \\
\hline & 1.0 Ref & 1.0 Ref & 1.0 Ref & 1.0 Ref \\
\hline
\end{tabular}

aScore includes frequency of violence multiplied by duration in a violent relationship.

${ }^{\mathrm{b}}$ Cases / controls; RR (95\% CI).

${ }^{\mathrm{c} N E}$, not estimable; Ref, referent.

increasing frequency and duration scores were not significantly associated with increased cervical dysplasia risk.

Table 3 shows the risk of cervical neoplasia associated with physical and sexual IPV frequencyduration scores by STI history. We found that higher sexual IPV scores (quartile 3) were associated with cervical cancer among women both with $(R R=10.4)$ and without $(R R=11.2)$ a history of an STI. Higher physical IPV scores (quartile 3) were significantly associated with cervical cancer only among those without an STI history. Similarly, increasing physical IPV scores (quartile 3) were associated with an increased risk of cervical dysplasia risk only among women who had never had an STI. This analysis is based on very small numbers and should be treated as exploratory in nature.

\section{DISCUSSION}

We found evidence for an association between IPV and cervical cancer. Further, risk of cervical cancer was associated with increasing IPV duration and frequency in a dose-dependent manner for both physical and sexual IPV. Although cervical dysplasia was associated with ever experiencing IPV, no dose-dependent association was observed.

Our finding that IPV is associated both with having an STI and with cervical cancer is consis- tent with findings of others who reported associations between IPV and STI, pelvic inflammatory disease, chronic pelvic pain, and bladder, kidney, or other urinary tract infections. ${ }^{13,19-22}$ These findings are also consistent with the growing literature showing that sexual assaults and abuse are associated with an increased risk of an STI, ${ }^{44}$ including infection with human immunodeficiency virus (HIV) ${ }^{45}$ and $\mathrm{HPV}, 46$ and with an increased risk of cervical dysplasia. ${ }^{24}$ Furthermore, it is clear that IPV has physical health effects on women beyond STI and injuries. ${ }^{1,2,7-15,47-50}$

We found evidence that IPV may be associated with cervical cancer indirectly through chronic stress and through an STI. If IPV were directly linked to cervical neoplasia through increasing risk of an STI, the RR for IPV and cervical neoplasia should be strongest within the strata of women with an STI, and IPV should not be associated with cervical neoplasia among women without an STI. If IPV were indirectly linked to cervical neoplasia through chronic stress, we might expect no difference in the stratum-specific RR. We did find that physical IPV scores were associated with cervical cancer among women both with and without a history of an STI. Interestingly, physical IPV scores were associated with cervical dysplasia and cancer only among women with no history of an STI. This supports the chronic stress mechanism for IPV's association with cervical neoplasia. By chronic stress, we mean the impact of anxiety and perceived stress 
associated with partner violence; this violence may occur over long periods of time and is unpredictable for the victim. Caution must be applied in interpreting these results, given the small numbers.

This report should be treated as exploratory or hypothesis generating in nature. As is true for exploratory studies, there are a number of limitations to their early work. STI was measured here based on the women's self-report. We do not have laboratory tests to confirm this history, nor do we have a measure of the etiological agent in cervical neoplasia, HPV. Additionally, we have no information on the HPV status of women's male partners. We undoubtedly misclassified STI exposure, but probably in a nondifferential manner, thus biasing the resulting RR toward the null. However, as we found that having a history of an STI was associated with both cervical cancer and dysplasia, we believe that this crude measure is a reasonable proxy. Another limitation of this study is the small number of invasive cervical cancer cases $(n=14)$ and our inability to specifically identify the grade of dysplasia. We were, however, able to verify through medical records that the self-reported cancers were indeed cancers. Further, because we asked about specific surgical treatment for an abnormal Pap smear, we are confident that women did have a high-grade or low-grade squamous intraepithelial lesion and not cervical atypia or inflammation. However, this group of women reporting treatment for a cervical lesion is heterogeneous and includes those with high-grade precancerous lesions and those with low-grade lesions. We might expect then that IPV would be more strongly associated with invasive cancer relative to this heterogeneous group of women with cervical lesions ranging in severity. Although this is a cross-sectional study, we were able to create temporally correct exposure measures for IPV, smoking, and STI as those prior to cervical neoplasia development and, thus, approximate an incident case-control study.

Because ensuring women's safety was a major concern, we did not wish to conduct follow-up phone interviews if women did not believe this was safe. We, therefore, disproportionately lost women currently in violent relationships. The prevalence of IPV in a current relationship among those completing the screener questionnaire was $7.3 \%$, and the IPV prevalence among those completing the follow-up questionnaire was $5.7 \%$. We explored whether this potential selection bias might affect our study findings by looking at the timing of IPV in a relationship and reporting cervical neoplasia. The crude OR for the association between IPV and cervical neoplasia were similar across different periods of IPV experience and suggest that our differential loss of those currently in violent relationships did not bias the resulting OR for IPV and cervical neoplasia (OR for IPV in a current relationship and cervical cancer $=4.0$, dysplasia $=1.20$; OR for IPV in a recent relationship and cervical cancer $=3.8$, dysplasia $=1.35$; OR for IPV in a past relationship and cervical cancer $=3.0$, dysplasia $=1.45$ )

To our knowledge, this is the first study to report an association between IPV and cervical neoplasia, including cancers. This study is relatively large $(n=1152)$, and we carefully measured IPV by the type (physical, sexual, and psychological violence), the frequency of the violence, and the duration in the violent relationship to assess the dose-dependent association between IPV and cervical neoplasia. We adjusted for the most significant confounders in these data (smoking and age), and we explored a possible mechanism by which IPV might be linked to cervical neoplasia.

\section{CONCLUSIONS}

These exploratory data suggest that IPV may be associated with higher-grade cervical lesions. However, additional, larger studies are needed to test this hypothesis. Further studies should include biological markers of HPV infection, evaluate the role of IPV and other chronic stressors on cervical neoplasia, and address the possibility that IPV and other chronic stressors may cause delayed Pap smear screening and, thereby, be associated with an increased risk of being detected with a higher-grade cervical lesion.

\section{REFERENCES}

1. Smith PH, Gittelman DK. Psychological consequence of battering. Implications for women's health and medical practice. NC Med J 1994;55:434.

2. Campbell J, Lewandowski LA. Mental and physical health effects of intimate partner violence on women and children. Psychiatr Clin North Am 1997;20:353.

3. Freund KM, Bak SM, Blackhall L. Identifying domestic violence in primary care practice. J Gen Intern Med 1996;11:44. 
4. Gin NE, Rucker L, Frayne S, Cygan R, Hubbell FA. Prevalence of domestic violence among patients in three ambulatory care internal medicine clinics. J Gen Intern Med 1991;6:317.

5. Rath GD, Jarratt LG, Leonardson G. Rates of domestic violence against adult women by men partners. J Am Broad Fam Pract. 1989;2:227.

6. Bullock L, McFarlane J, Bateman LH, Miller V. The prevalence and characteristics of battered women in a primary care setting. Nurse Pract 1989;14:47.

7. Plichta S. The effects of woman abuse on health-care unitization and health status: A literature review. Women's Health Issues 1992;2:154.

8. Haber J. Abused women and chronic pain. Am J Nurs 1985;85:1010.

9. Appleton W. The battered women syndrome. Ann Emerg Med 1980;9:84.

10. Tilden VP, Shepherd P. Increasing the rate of identification of battered women in an emergency department: Use of a nursing protocol. Res Nurs Health 1987;10:209.

11. McLeer SV, Anwar R. A study of battered women presenting in an emergency department. Am J Public Health 1989;79:65.

12. Bergman B, Brismar B, Nordin C. Utilisation of medical care by abused women. Br Med J 1992;305:27.

13. Coker AL, Smith PH, Bethea L, Kling MR, McKeown RE. Physical health consequences of physical and psychological intimate partner violence. Arch Fam Med 2000;9:1.

14. Drossman DA, Lesser J, Nachman G, et al. Sexual and physical abuse in women with function or organic gastrointestinal disorders. Ann Intern Med 1990;113: 828.

15. Talley NJ, Fett SL, Zinsmeister AR, Melton LJ. Gastrointestinal tract symptoms and self-reported abuse: A population-based study. Gastroenterology 1994;107: 1040.

16. Hogston P. Irritable bowel syndrome as a cause of pelvic pain in women attending a gynecologic clinic. Br Med J 1987;294:934.

17. Chapman JD. A longitudinal study of sexuality and gynecologic health in abused women. J Am Osteopath Soc 1989;89:619.

18. Domino JV, Haber JD. Prior physical and sexual abuse in women with chronic headache: Clinical correlates. Headache 1987;27:310.

19. Bergman B, Brismar B. A 5-year follow-up study of 117 battered women. Am J Public Health 1991;81: 1486.

20. Campbell JC, Alford P. The dark consequences of marital rape. Am J Nurs 1989;89:946.

21. Schei B. Physically abusive spouse-A risk factor for pelvic inflammatory disease. Scand J Prim Health Care 1991;9:41.

22. Rapkin AJ, Kames LD, Darke LL, et al. History of physical and sexual abuse in women with chronic pelvic pain. Obstet Gynecol 1990;76:92.

23. Plitcha SB. Violence, health and use of health services.
In: Women's health and care seeking behaviors. Baltimore, MD: Johns Hopkins University Press, 1997:237.

24. Coker AL, Patel N, Krishnawami S, Schmidt W, Richter D. Childhood forced sex and cervical neoplasia among women prison inmates. Violence against Women 1998;4:595.

25. Cohen S, Frank E, Doyle WJ, et al. Types of stressors that increase susceptibility to the common cold in healthy adults. Health Psychol 1998;17:214.

26. Cohen S, Doyle WJ, Skoner DP. Psychological stress, cytokine production, and severity of upper respiratory illness. Psychosom Med 1999;61:175.

27. Leserman J, Petitto JM, Perkins DO, et al. Severe stress, depressive symptoms, and changes in lymphocyte subsets in human immunodeficiency virusinfected men: A 2-year follow-up study. Arch Gen Psychiatry 1997;54:279.

28. Evans EL, Leserman J, Perkins DO, et al. Stress-associated reductions of cytotoxic T lymphocytes and natural killer cells in asymptomatic HIV infection. Am J Psychiatry 1995;152:543.

29. Hildesheim A, Schiffman MH, Tsukui T, et al. Immune activation in cervical neoplasia: Cross-sectional association between plasma sIL-2R levels and disease. Cancer Epidemiol Biomark Prev 1997;6:807.

30. Ung A, Kramer TR, Schiffman M, et al. Soluble interleukin 2 receptor levels and cervical neoplasia: Results form a population-based case-control study in Costa Rica. Cancer Epidemiol Biomark Prev 1999;8: 249.

31. Hilakivi-Clarke L, Dickson RB. Stress influence on development of hepatocellular tumors in transgenic mice overexpressing TGR alpha. Acta Oncol 1995;34: 907.

32. Ben-Eliyahu S, Page GG, Yirmiya R, Shakhar G. Evidence that stress and surgical interventions promote tumor development by suppressing natural killer cell activity. Int J Cancer 1999;80:880.

33. Coker AL, Smith PH, McKeown RE, King MR. Frequency and correlates of intimate partner violence by type: Physical, sexual, and psychological battering. Am J Public Health 2000;90:553.

34. Hudson WW. Partner abuse scale: Physical. Tempe, AZ: Walmyr Publishing Co, 1991.

35. Attala J, Hudson W, McSweeney M. A partial validation of two short-form partner abuse scales. Women Health 1994;21:135.

36. Smith PH, Earp JA, DeVellis R. Development and validation of the Women's Experience with Battering (WEB) Scale. Women Health 1995;1:273.

37. Smith PH, Tessaro I, Earp JA. Women's experience with battering: A conceptualization from qualitative research. Women Health Issues 1995;5:173.

38. Smith PH, Smith JB, Earp JA. Beyond the measurement trap: A reconstructed conceptualization and measurement of woman battering. Psychol Women Q 1999;23:177.

39. McFarlane J, Parker B, Soeken S, Bullock L. Assessing for abuse during pregnancy: Severity and frequency 
of injuries an associated entry into prenatal care. JAMA 1992;267:3176.

40. U.S. Bureau of the Census. National Health Interview Survey Filed Representative's Manual. HIS-100. U.S. Department of Commerce acting as a collecting agent for the U.S. Public Health Service, 1994.

41. Breslow NE, Day NE. Statistical methods in cancer research. Volume I: The analysis of case-control studies. WHO International Agency for Research on Cancer, No. 32, 1980.

42. Zhang J, Yu KF. What's the relative risk? A method of correcting the odds ratio in cohort studies of common outcomes. JAMA 1998;280:1690

43. Rothman KJ, Greenland S. Modern epidemiology, 2nd ed. Philadelphia: Lippincott-Raven, 1998.

44. Vermund SH, Rodriguez T, Macleod AS, Kelley KF. History of sexual abuse in incarcerated adolescents with gonorrhea or syphillis. J Adolesc Health Care 1990;11:449.

45. Zierler S, Feingold L, Laufer D, Velentgas P, Gordon L, Meyer K. Adult survivors of childhood sexual abuse and subsequent risk of HIV infection. Am J Public Health 1991;81:572.

46. Gutman LT, St Claire K, Herman-Giddens ME, Johnston WW, Phelps WC. Evaluation of sexually abused and non-abused young girls for intravaginal human papillomavirus infection. Am J Dis Child 1992;146:694.
47. Plichta S. The effects of women abuse on health-care utilization and health status: A literature review. Women's Health Issues 1992;2:154.

48. Wagner PJ, Mongan PF. Validating the concept of abuse: Women's perceptions of defining behaviors and the effects of emotional abuse on health indicators. Arch Fam Med 1998;7:25.

49. Campbell J, Torres S, Ryan J, et al. Physical and nonphysical partner abuse and other risk factors for low birth weight among full term and preterm babies: A multiethnic case-control study. Am J Epidemiol 1999; 150:714

50. Smith $\mathrm{PH}$, Edwards G. Battering among reproductive age women: Prevalence and health implications. Presentation at the 4th Annual Family Violence Conference, Durham, New Hampshire, July 2, 1997.

Address reprint requests to: Ann L. Coker, Ph.D. University of South Carolina School of Public Health Department of Epidemiology and Biostatistics 800 Sumter Street Columbia, SC 29208 
Copyright of Journal of Women's Health \& Gender-Based Medicine is the property of Mary Ann Liebert, Inc. and its content may not be copied or emailed to multiple sites or posted to a listserv without the copyright holder's express written permission. However, users may print, download, or email articles for individual use. 